\title{
Factors Associated with Hypertensive Disorder of Pregnancy in Kombolcha
}

\section{Mastewal Arefaynie Temesgen}

Department of Public health, College of Medicine and Health Sciences, Wollo University, Ethiopia

*Corresponding author: Mastewal Arefaynie Temesgen, Department of Public health, College of Medicine and Health Sciences, Wollo University, Ethiopia, E-mail: marefaynie@yahoo.com

Received date: September 07, 2017; Accepted date: October 3, 2017; Published date: October 09, 2017

Copyright: (C) 2017 Temesgen MA. This is an open-access article distributed under the terms of the Creative Commons Attribution License, which permits unrestricted use, distribution, and reproduction in any medium, provided the original author and source are credited.

\begin{abstract}
Background: Hypertensive disorder of pregnancy is a leading cause of maternal and prenatal mortality. It is also a major cause of pregnancy complication, causing premature delivery, foetal growth retardation. In addition, it has long-term health effects, like, chronic hypertension, kidney failure and nervous system disorders. Since no study was conducted so far in Kombolcha town, exploring determinants of hypertensive disorder of pregnancy is important to take important preventions in the study area. The objective of this study is to assess determinants of hypertensive disorders of pregnancy among pregnant women attending antenatal and delivery in Kombolcha town.
\end{abstract}

Methods: A facility based unmatched case control study design was conducted among pregnant women attending antenatal and delivery care services in health facilities of Kombolcha town. 117 cases and 353 controls were participated in the study. For data collection, a structured and pretested standard questionnaire was used. Descriptive statistics were done to characterize the study population using different variables. Bivariate and multiple logistic regression models were fitted to control confounding factors. Odds ratios with $95 \%$ confidence intervals were computed to identify determinants of hypertensive disorders of pregnancy.

Result: In this study participants who could not read and write were 2.66 (AOR, 2.643, 95\% Cl, 1.106-6.319) and 4.4 (AOR, 4.417, 95\% Cl, 1.583-12.327) times more risk of developing hypertensive disorder of pregnancy than those who can read and write, attending their primary education respectively. Women who have previous history of preeclampsia were 4.4 (AOR, 4.224, 95\% Cl, 2.064-8.645) times more risk of hypertensive disorder of pregnancy than their counterparts.

Conclusion and recommendation: In this study, lower educational status, previous history of preeclampsia and family history of hypertension were determinants of hypertensive disorders of pregnancy. Health care providers should give high attention for illiterate, previous history of preeclampsia to initiate ANC to prevent, early diagnosis and treatment of hypertensive disorders of pregnancy in pregnant women to reduce maternal and child complications.

Keywords: Factors; Hypertensive; Pregnancy; Kombolcha

Abbreviations: ANC: Anti Natal Care; AOR: Adjusted Odds Ratio; CI: Confidence Interval; COR: Crude Odds Ratio; DBP: Diastolic Blood Pressure; HDP: Hypertensive Disorder of Pregnancy; SBP: Systolic Blood Pressure

\section{Introduction}

Hypertensive disorder of pregnancy (HDP), defined as high blood pressure during pregnancy; is one of the direct cause of maternal and child mortality [1-3]. It is measured by blood pressure level greater than $140 / 90 \mathrm{~mm} \mathrm{Hg}$ after 20 weeks gestation. Severe forms of HDP are reflected through blood pressure levels of $160 / 100 \mathrm{~mm} \mathrm{Hg}$ and more $[4,5]$.

In developing countries pregnant women suffered by pregnancy related complications and physiological effect of pregnancies. HDP which includes preeclampsia and eclampsia is a major public health problem in sub Saharan countries. It is common medical complication of pregnancy responsible for maternal and child mortality [6-11]. Its effect is high when a woman has chronic disease like renal and diabetes mellitus [12]. It complicates the health of the new born through preterm delivery, low birth, hypothermia and would end up as a still birth or abortion $[13,14]$.

The Ethiopian government plane to reduce maternal mortality due to pregnancy related complication like hypertension, pre partum and postpartum bleeding, but the incidence of hypertension and its complication on mothers and new born is prevalent as indicted by different study conducted in different parts of the country [14-16].

Blood pressure level is more effectively controlled through enhancing the pregnant mothers' self- care knowledge. However, it appears most pregnant women with pregnancy related hypertension lack adequate knowledge to look after themselves during pregnancy in order to control the blood pressure level. Even though there are few studies exploring hypertension during pregnancy in Ethiopia, there has no any study conducted yet in the current study area of my interest. Therefore, this study will be conducted to identify factors associated with hypertension during pregnancy. So this study aimed to assess the associated factors of pregnancy related hypertension and finally the findings will provide information on health status of pregnant mothers 
in the study setting and the recommendation will point out appropriate actions for decision makers.

\section{Method}

\section{Study setting}

A facility based unmatched cases-controls study was conducted in health facilities of Kombolcha town, south Wollo zone, Amhara regional state of Ethiopia. Kombolcha is located $372 \mathrm{~km}$ away from the capital city of Ethiopia, Addis Ababa. It has five health centres and one family guidance association providing maternal health services (antenatal, delivery and post natal care).

\section{Source population}

Both source and study populations were pregnant women who had visited antenatal and delivery service wards of health facilities in Kombolcha town from September 20, 2016-January 26, 2017. Pregnant women who were admitted for delivery service and unable to respond during interview were excluded from the study.

The sample size was calculated using Epi Info version 7.1.5.2 software for unmatched case control study. It was determined by taking an important independent predictor (age of pregnant women) (20) which gave maximum sample size (the proportion of exposure in controls group on age greater than 30 was 21.1 with odds ratio of 2 with the following assumptions $80 \%$ power, $5 \%$ level of significance, $10 \%$ non-response rate, 1:3 Ratio (case to control ratio), then the total sample size was about 470 (case 117 and 353 and the total sample size is 470). Both institutions were included purposefully. By assuming clients were randomly distributed all cases were included consecuantivly and three controls preceding the case were included consecuantivly till adequate sample was taken from the two hospitals.

\section{Study variables and measurement}

Hypertensive disorder of pregnancy is the dependent variable of this study. Whereas Socio demographic characteristics (age, residence, religion, ethnicity, marital status, educational status, occupational status), Medical and reproductive history and Women behavioural factors (alcohol consumption, chat chewing, tobacco use) were independent variables.

Cases are pregnant women's who had visited health institution for antenatal care and delivery service and had confirmed diagnosis of hypertensive disorders of pregnancy. Controls are pregnant women's who had visited health institution for antenatal care and delivery service and had no evidence of hypertensive disorders of pregnancy.

Blood pressure of pregnant mothers was measured manually with a validated sphygmomanometer in sitting position at the right upper arm after the mothers take rest at ANC and delivery ward clinic for five minutes and classify as pregnancy related hypertension which is systolic blood pressure $\geq 140 \mathrm{~mm} \mathrm{Hg}$ or diastolic pressure $\geq 90 \mathrm{~mm} \mathrm{Hg}$ which occurs 20 weeks of gestational age on wards on previously normal hypertensive woman after taking two times similar measurements and considered as cases. The presence of edema at face, hands will be investigated by physical examination. And systolic blood pressure $\geq 160 \mathrm{~mm} \mathrm{Hg}$ or diastolic pressure $\geq 110 \mathrm{~mm} \mathrm{Hg}$ as sever hypertensive disorder of pregnancy. Preeclampsia is gestational hypertension [systolic blood pressure $(\mathrm{SBP}) \geq 140 \mathrm{~mm} \mathrm{Hg}$ and/or diastolic blood pressure (DBP) $\geq 90 \mathrm{~mm} \mathrm{Hg}$ after 20 weeks of gestation plus the presence of proteinuria.

\section{Data quality control}

In order to assure the quality of data the following measures were taken: questionnaire was prepared in English and translated to local language Amharic and re translated back to English. Training was given for both data collectors and supervisors for two days. Pretest of tool was done in non- selected health centre (Dessie) on $5 \%$ of the sample which is not part of the study area before conducting the main study and the lessons obtained from the pre-test were included in the final tool. Supervision of data collectors was made for each hospital by supervisor and investigators.

\section{Data analysis}

The completed questionnaire was checked for completeness and consistency by the principal investigator and the coordinators each day and code was given to the completed questionnaire. The data were entered using Epi Info version 3.5.1 and transferred to SPSS 21.0 statistical package for analysis. Data cleaning was performed to check for accuracy, consistencies, and values. Then errors were identified and corrected. Univariat analysis using frequency technique was used to describe the data according to some important characteristics of the study subjects. Then the data were expressed in percentage, means, medians and standard deviations. Then bivariate logistic regression techniques was used to see the crude association between the independent variables and the dependent variable and the strength of association was expressed in odds ratio $(\mathrm{OR})$. Variables with $(\mathrm{p}<0.25)$ were analyzed by using multivariate logistic regression to control confounding effects.

\section{Ethical consideration}

In this study, the principal investigator was followed the basic ethical principles of respect for persons, beneficence and justice.

Ethical clearance obtained from the institutional review board of Wollo University, department of public health, college of medicine and health science. Written permission obtained from District health department and respective health centres. During data collection process, which held by asking each women, their willingness to participate and informing the significance of the study, their rights to participate, withdraw, and refuse the interview at any time. In addition, written informed consent also gained for their readiness to participant. After ensuring the participation, the data was collected. The information gained interview strictly kept confidential, safe and privacy kept. Generally, the data obtained from the participants used for this study only. Besides data collection, a woman who had hypertensive disorder of hypertension advised to follow antenatal care strictly and get appropriate treatment for the current and feature pregnancy.

\section{Results}

\section{Socio demographic characteristics}

In this study 117 cases of hypertensive disorder of pregnancy and 353 control women who visit antenatal care and delivery services were interviewed. Among cases 66 and 51 were detected during antenatal 
Page 3 of 5

and delivery care respectively. From cases 12 were developing preeclampsia and 17 were severe HDP (Table 1).

\begin{tabular}{|c|c|c|c|}
\hline \multirow{2}{*}{ Variable } & Cases $(n=117)$ & $\begin{array}{l}\text { Controls } \\
(n=353)\end{array}$ & Total (470) \\
\hline & N (\%) & $\mathrm{N}(\%)$ & N (\%) \\
\hline \multicolumn{4}{|l|}{ Age } \\
\hline $15-24$ & $42(36.0)$ & 118 (33.5) & $160(24.8)$ \\
\hline $25-34$ & $59(50.3)$ & $165(46.7)$ & $224(47.7)$ \\
\hline $35-44$ & $12(10.3)$ & $57(16.1)$ & 69 (14.8) \\
\hline$>44$ & $4(3.4)$ & $13(3.7)$ & $17(3.7)$ \\
\hline \multicolumn{4}{|l|}{ Residence } \\
\hline Urban & $71(60.7)$ & $175(59.8)$ & $246(52.4)$ \\
\hline Rural & 46 (39.3) & $142(40.2)$ & $224(47.6)$ \\
\hline \multicolumn{4}{|l|}{ Religion } \\
\hline Orthodox & 69 (59.0) & $238(67.4)$ & $307(65.3)$ \\
\hline Muslim & 37 (31.6) & 95 (26.9) & $132(28.1)$ \\
\hline Protestant & $11(9.4)$ & $20(5.7)$ & $31(6.6)$ \\
\hline \multicolumn{4}{|l|}{ Ethnicity } \\
\hline Amhara & $111(94.9)$ & $336(95.2)$ & 447 (95.1) \\
\hline Tigray & $6(5.1)$ & $17(4.8)$ & $23(4.9)$ \\
\hline \multicolumn{4}{|l|}{ Marital Status } \\
\hline Single & $11(9.4)$ & $24(6.8)$ & $35(7.4)$ \\
\hline Married & 98 (83.8) & $317(89.8)$ & $415(88.3)$ \\
\hline Divorced & $8(6.8)$ & $12(3.4)$ & $20(4.3)$ \\
\hline \multicolumn{4}{|l|}{ Educational Status } \\
\hline $\begin{array}{l}\text { Not Read And } \\
\text { Write }\end{array}$ & $17(14.5)$ & $103(29.2)$ & $120(25.5)$ \\
\hline Read And Write & $58(49.6)$ & $135(38.3)$ & $193(41.1)$ \\
\hline Primary School & $23(19.7)$ & $52(14.7)$ & $75(16.0)$ \\
\hline $\begin{array}{l}\text { Secondary And } \\
\text { Above }\end{array}$ & $19(16.2)$ & $63(17.8)$ & $82(17.4)$ \\
\hline \multicolumn{4}{|l|}{ Occupation } \\
\hline Unemployed & $62(53.0)$ & $181(51.3)$ & $243(51.7)$ \\
\hline Employed & $55(47.0)$ & $172(48.7)$ & $227(48.3)$ \\
\hline
\end{tabular}

Table 1: Socio demographic characteristics of women who attend ANC and delivery care in health facilities of Kombolcha town, September 20, 2016 -January, 26, 2017.

From the total of 65 cases and 195 controls, $71(60.7 \%)$ of cases and 175 (59.8\%) of the controls were urban residents. Majority, 69 (59.0\%) cases and $238(67.4 \%)$ of the controls were orthodox religion followers. Almost all 111 (94.9\%) of case and 336 (95.2\%) controls were Amhara ethnic groups.
Majority of the women were married, 98 (83.8\%) cases and 317 (89.8\%) controls respectively. $19(16.2 \%)$ of cases and 63 (17.8) controls had attend secondary and above level of education.

\section{Reproductive and medical history of clients}

The study revealed that nearly one fourth of, $16(24.6 \%)$ cases and 50 (25.6\%) of controls were prim-gravid. In addition, $48(73.8 \%)$ cases and $138(70.8 \%)$ of controls were nulliparous. only 14 (21.5\%) of cases and one fourth of 49 (25.1\%) of controls had ANC visit four times during their current pregnancy. 19 (29.2\%) of cases and one third of 72 (36.9\%) of controls had get their first pregnancy before 19 years old.

Nearly half $29(44.6 \%)$ of cases and $103(52.8 \%)$ controls have greater than 35 month inter-pregnancy space. About half of 34 (52.3\%) cases and $89(45.6 \%)$ of controls were give female child birth. Majority of both cases and controls had a single pregnancy 61 (93.8\%) and 190 (97.4\%) respectively.

Nearly half of $29(44.6 \%)$ cases and $25(12.8 \%)$ controls had previous history of preeclampsia. Only $9(13.8 \%)$ of cases and 10 (5.1\%) controls had family history of diabetes mellitus (DM). 33 (50.8\%) of cases and 33 (16.9\%) of controls had family history of hypertension (HTN).

About one-fourth of (26.2\%) cases and (29.2\%) controls had history of abortion. Only $1(1.5 \%)$ of cases and $5(2.6 \%)$ of controls were chat chewers. $100 \%$ of both cases and controls did not smoke cigarette (Table 2)

\begin{tabular}{|c|c|c|c|}
\hline \multirow[t]{2}{*}{ Variable } & \multirow{2}{*}{$\begin{array}{l}\begin{array}{l}\text { Cases } \\
(n=117)\end{array} \\
N(\%)\end{array}$} & \multirow{2}{*}{$\begin{array}{l}\begin{array}{l}\text { Controls } \\
(\mathrm{n}=353)\end{array} \\
\mathrm{N}(\%)\end{array}$} & \multirow[t]{2}{*}{$\begin{array}{l}\text { Total } \\
\text { (470) }\end{array}$} \\
\hline & & & \\
\hline \multicolumn{4}{|l|}{ Gravid } \\
\hline Primgravid & $29(24.8)$ & $100(28.4)$ & $129(27.4)$ \\
\hline Multigravida & $88(75.2)$ & $253(71.6)$ & $341(72.6)$ \\
\hline \multicolumn{4}{|l|}{ Parity } \\
\hline Prim parous & $27(23.1)$ & $107(29.3)$ & $134(28.5)$ \\
\hline Multiparous & $90(76.9)$ & $246(69.7)$ & $336(71.5)$ \\
\hline \multicolumn{4}{|c|}{ Age of first pregnancy (15-49) } \\
\hline $15-19$ & $37(31.6)$ & $132(37.4)$ & $169(36.0)$ \\
\hline $20-24$ & $71(60.7)$ & $202(57.2)$ & $273(58.0)$ \\
\hline $25-29$ & $9(7.7)$ & $19(5.4)$ & $28(6.0)$ \\
\hline \multicolumn{4}{|c|}{ Time interval between pregnancy } \\
\hline No interval & $30(25.6)$ & $88(24.9)$ & $118(25.1)$ \\
\hline 1-24 months & $31(26.5)$ & $74(21.0)$ & $105(22.3)$ \\
\hline 25-34 months & $5(4.3)$ & $18(5.1)$ & $23(4.9)$ \\
\hline$\geq 35$ months & $51(43.6)$ & $173(49.0)$ & $132(47.7)$ \\
\hline \multicolumn{4}{|c|}{ Previous history of preeclampsia } \\
\hline No & $65(55.6)$ & $303(85.8)$ & $368(78.3)$ \\
\hline Yes & $52(44.4)$ & $50(14.2)$ & $102(21.7)$ \\
\hline
\end{tabular}


Citation: Temesgen MA (2017) Factors Associated with Hypertensive Disorder of Pregnancy in Kombolcha. Clinics Mother Child Health 14: 274. doi:10.4172/2090-7214.1000274

Page 4 of 5

\begin{tabular}{|c|c|c|c|}
\hline \multicolumn{4}{|c|}{ Family history of DM } \\
\hline No & $106(90.6)$ & $337(95.5)$ & $443(94.3)$ \\
\hline Yes & $11(9.4)$ & $16(4.5)$ & $27(5.7)$ \\
\hline \multicolumn{4}{|c|}{ Family history of HTN } \\
\hline No & $55(47.0)$ & $290(82.2)$ & $345(73.4)$ \\
\hline Yes & $62(53.0)$ & $63(17.8)$ & $125(26.6)$ \\
\hline \multicolumn{4}{|c|}{ History of abortion } \\
\hline No & $86(73.5)$ & $256(72.5)$ & $342(72.8)$ \\
\hline Yes & $31(26.5)$ & $97(27.5)$ & $128(27.2)$ \\
\hline \multicolumn{4}{|c|}{ History of DM } \\
\hline No & $114(97.4)$ & $353(100)$ & $467(99.4)$ \\
\hline Yes & $3(2.6)$ & $0(0)$ & $3(0.6)$ \\
\hline \multicolumn{4}{|c|}{ History of kidney disease } \\
\hline No & $83(70.9)$ & $326(92.4)$ & $409(87.1)$ \\
\hline Yes & $34(29.1)$ & $27(7.6)$ & $61(12.9)$ \\
\hline \multicolumn{4}{|c|}{ Chat chewing } \\
\hline No & $2(1.7)$ & $8(2.3)$ & $10(2.1)$ \\
\hline Yes & $115(98.3)$ & $345(97.7)$ & $460(97.9)$ \\
\hline \multicolumn{4}{|c|}{ Alcohol consumption } \\
\hline No & $31(26.5)$ & $72(20.4)$ & $103(21.9)$ \\
\hline Yes & $86(73.5)$ & $281(79.6)$ & $367(78.1)$ \\
\hline
\end{tabular}

Table 2: Reproductive and medical history of women who attend ANC and delivery care in health facilities of Kombolcha town, September 20, 2016 -January, 26, 2017.

\section{Determinants of preeclampsia}

Different factors were analyzed for their independent effect on HDP. Delivering women who could not read and write were two point six (AOR, 2.643, 95\% CI, 1.106-6.319) and abut four (AOR, 4.417, 95\% CI, 1.583-12.327) times more risk of developing HDP than those who can read and write and attending their primary education respectively.

Delivering women who had previous history of preeclampsia were 4.2 (AOR, 4.2, 95\% CI, 2.1-8.6) times more risk of HDP development as compared to these who had no previous experience of preeclampsia.

Delivering women who had Family History of hypertension were about 4 (AOR, 3.9, 95\% CI, 2.0-7.8) times more risk of developing HDP as compared to these who had no family history of hypertension (Table 3).

\section{Discussion}

Recognizing factors that affect hypertensive disorder of pregnancy in pregnant women had a paramount important to reduce maternal as well as child mortality and morbidity.

In the present study women who had family history of hypertension were about five times at more risk of developing HDP than their counterparts. The study is in line with studies done at Dessie referral hospital, Bangladesh, Derashie [13,14,17].

\begin{tabular}{|c|c|c|c|c|c|}
\hline Variables & $\begin{array}{l}\text { Cases } \\
(n=117)\end{array}$ & $\begin{array}{l}\text { Controls } \\
(n=353)\end{array}$ & $\begin{array}{l}\text { COR } \\
(95 \% \mathrm{Cl})\end{array}$ & $\begin{array}{l}\text { AOR } \\
(95 \% \mathrm{Cl})\end{array}$ & p-value \\
\hline \multicolumn{6}{|l|}{ Religion } \\
\hline Orthodox & $69(59.0)$ & $\begin{array}{l}238 \\
(67.4)\end{array}$ & 1 & & \\
\hline Muslim & $37(31.6)$ & $95(26.9)$ & $\begin{array}{l}1.343(0.675- \\
2.348)\end{array}$ & & \\
\hline Protestant & $11(9.4)$ & $20(5.7)$ & $\begin{array}{l}1.897(1.203- \\
14.342)\end{array}$ & & \\
\hline \multicolumn{6}{|c|}{ Educational Status } \\
\hline $\begin{array}{l}\text { Not Read and } \\
\text { Write }\end{array}$ & $17(14.5)$ & $\begin{array}{l}103 \\
(29.2)\end{array}$ & 1 & 1 & \\
\hline $\begin{array}{l}\text { Read and } \\
\text { Write }\end{array}$ & $58(49.6)$ & $\begin{array}{l}135 \\
(38.3)\end{array}$ & $\begin{array}{l}2.603(1.171- \\
5.848)\end{array}$ & $\begin{array}{l}2.643 \\
(1.106- \\
6.319)\end{array}$ & 0.029 \\
\hline $\begin{array}{l}\text { Primary } \\
\text { School }\end{array}$ & $23(19.7)$ & $52(14.7)$ & $\begin{array}{l}2.679(1.499- \\
9.529)\end{array}$ & $\begin{array}{l}4.417 \\
(1.583- \\
12.327)\end{array}$ & $0.005^{*}$ \\
\hline $\begin{array}{l}\text { Secondary } \\
\text { and Above }\end{array}$ & $19(16.2)$ & $63(17.8)$ & $\begin{array}{l}1.872(0.783- \\
4.855)\end{array}$ & & \\
\hline \multicolumn{6}{|c|}{ History of Kidney disease } \\
\hline No & $83(70.9)$ & $\begin{array}{l}326 \\
(92.4)\end{array}$ & 1 & & \\
\hline Yes & $34(29.1)$ & $27(7.6)$ & $\begin{array}{l}4.946(1.980- \\
9.123)\end{array}$ & & \\
\hline \multicolumn{6}{|c|}{ Previous history of preeclampsia } \\
\hline No & $65(55.6)$ & $\begin{array}{l}303 \\
(85.8)\end{array}$ & 1 & 1 & \\
\hline Yes & $52(44.4)$ & $50(14.2)$ & $\begin{array}{l}4.848(2.875- \\
10.436)\end{array}$ & $\begin{array}{l}4.224 \\
(2.064- \\
8.645)\end{array}$ & $0.000^{\star * \star}$ \\
\hline \multicolumn{6}{|c|}{ Family history of HTN } \\
\hline No & $55(47.0)$ & $\begin{array}{l}290 \\
(82.2)\end{array}$ & 1 & 1 & \\
\hline Yes & $62(53.0)$ & $63(17.8)$ & $\begin{array}{l}5.189(2.741- \\
9.351)\end{array}$ & $\begin{array}{l}3.941 \\
(1.984- \\
7.826)\end{array}$ & $0.000^{* * *}$ \\
\hline \multicolumn{6}{|c|}{ Family history of DM } \\
\hline No & $\begin{array}{l}106 \\
(90.6)\end{array}$ & $\begin{array}{l}337 \\
(95.5)\end{array}$ & 1 & & \\
\hline Yes & $11(9.4)$ & $16(4.5)$ & $\begin{array}{l}2.185 \text { (1.151- } \\
7.679)\end{array}$ & & \\
\hline
\end{tabular}

Table 3: Factors associated with HDP women who attend ANC and delivery care in health facilities of Kombolcha town, September 20, 2016 -January, 26, 2017. 
Page 5 of 5

Educational attainment of women is another determinant of developing HDP $[6,8,17]$. Illiterate mothers were more likely to have HDP than their counter parts. This is could be educated mothers are likely to be aware of pregnancy related complications (due to use of contraception, antenatal care) and its consequences, likely to marry educated husband that facilitate couples discussion on maternal health care utilization, likely to be autonomous in decision making and hence meting her reproductive need when she want. Education may also increases health seeking behaviours of women.

Previous history of preeclampsia increases risk of developing HDP in feature pregnancies. The result is supported by other studies history of previous preeclampsia is a known risk factor for a new event in a future pregnancy $[12,15,17]$.

Limitations of the study are it mainly focuses on individual level factors and factors related to the health system and the service providers did not included, the socio cultural factors and related misconception on early initiation of antenatal care and women who were give delivery at home were not assessed. Since it is cross-sectional study cause effect relation is not established. Further research is needed on the outcome of HDP on women by using follow up study.

\section{Conclusion and Recommendations}

Lower educational status, previous history of preeclampsia and family history of hypertension are predictors of HDP.

Based on the findings the following recommendations were given. As maternal health services (ANC) is potential time for counselling of mothers about pregnancy related complications, counselling about HDP should get more focus. There is great need to prioritize education of girls to empower them to use different interventions which reduces the occurrence of different pregnancy related complications, particularly HDP, to encourage women to be supported by their spouses and to promote utilization of different maternal health services. In addition there is need to focus on pregnant women with family and previous history of preeclampsia and hypertension by strengthening client-provider interaction especially through maternal and child health services.

\section{Declarations}

\section{Ethics approval and consent of participants}

The study proposal got ethical approval from Wollo University, health science college ethical review committee. Administrative bodies of respective town and hospital administrations were asked for their permission of the research to be conducted in the area. Informed oral and written consent was obtained from participants.

\section{Availability of data and materials}

"The data that support the findings of this study has a sort of identifier of individual participants and researcher reserved to send it".

\section{Competing interests}

The author declares that he has no competing interest.

\section{Funding}

The funding for this study was Wollo University.

\section{Acknowledgements}

I would like to thank all contributors those who made the finalization of this research.

\section{References}

1. Association of Ontario Midwives (2012) Clinical practice Guideline No 15: hypertensive disorder of pregnancy.

2. Coghill AE, Hansen S, Littman AJ (2011) Risk factors for Eclampsia: a population-based study in Washington State, 1987-2007. Am J Obstet Gynecol 205: 553.e1-553.e7.

3. Leeman L, Fontaine P (2008) Hypertensive Disorders of Pregnancy, American Family Physician 78: 93-100.

4. National Heart, Lung, and Blood Institute (2000) Report of the National High Blood Pressure Education Program Working Group on High Blood Pressure in Pregnancy. Am J Obstet Gynecol 183: S1-S22.

5. Saftlas AF, Wang W, Risch H, Woolson R, Hsu CD, et al. (2000) Prepregnancy body mass index and gestational weight gain as risk factors for preeclampsia and transient hypertension. Ann Epidemiol 10: 475.

6. Belogolovkin V, Engel S, Savitz D, Chelimo C, Siega-Riz AM, et al. (2006) Weight gain velocity in relation to the development of gestational hypertension and or preeclampsia. Am J Obstet Gynecol 195: S127.

7. Vasheqani F, Atarod ZA (2006) comparision between Plasma lipids concentration in preeclamptic and normotensive women. J Mazandaran Univ Med Sci 53: 92-96.

8. Vahidrodsari F, Ayaty S, Tourabizadeh A, Ayat-Allahi H, Esmaeli H, et al. (2008) Serum calcium and magnesium in preeclamptic and normal pregnancies: a comparative study. J Reprod Infertil 9: 256-262.

9. Sibai B, Lindheimer M, Hauth J, Caritis S, VanDorsten P, et al. (1998) Risk factors for preeclampsia, abruptio placentae, and adverse neonatal outcomes among women with chronic hypertension. N Engl J Med 339: 667-671.

10. Chen CL, Cheng Y, Wang PH, Juang CM, Chiu LM, et al. (2000) Review of pre-eclampsia in Taiwan: a multi-institutional study. Zhonghua Yi Xue Za Zhi (Taipei) 63: 869-875.

11. Lee CJ, Hsieh TT, Chiu TH, Chen KC, Lo LM, et al. (2000) Risk factors for pre-eclampsia in an Asian population. Int J Gynaecol Obstet 70: 327-333.

12. Garner PR, D’Alton ME, Dudley DK, Huard P, Hardie M (1990) Preeclampsia in diabetic pregnancies. Am J Obstet Gynecol 163: 505-508.

13. Appel LJ (2003) Lifestyle modification as a means to prevent and treat high blood pressure. J Am Soc Nephrol 14: S99-S102

14. Midgley J, Mathew A, Greenwood C, Logan A (1996) Effect of reduced dietary sodium on blood pressure: a meta-analysis of randomised controlled trials. JAMA 275: 1590-1597.

15. Solomon CG, Seely EW (2001) Brief review: hypertension in pregnancy: a manifestation of the insulin resistance syndrome? Hypertension 37: 232-239.

16. CSA (2016) Ethiopia demographic and health survey: Central Statistical Agency; Calverton, USA.

17. Ahmed SS, Sultana N, Begum ML, Sultana L, Abedin MF, et al. (2017) pregnancy induced hypertension and associated factors among pregnant women. J Gynecol Women's Health 3: 1-6. 